Article

\title{
Sustainable Development of Chitosan/Calotropis procera-Based Hydrogels to Stimulate Formation of Granulation Tissue and Angiogenesis in Wound Healing Applications
}

\author{
Muhammad Zahid ${ }^{1}$ (D), Maria Lodhi ${ }^{1}$, Zulfiqar Ahmad Rehan ${ }^{2, *}$, Hamna Tayyab ${ }^{1}$, Talha Javed ${ }^{3,4}$ (D), \\ Rubab Shabbir ${ }^{3}{ }^{(D)}$, Ahmed Mukhtar ${ }^{4}$ (D), Ayman EL Sabagh ${ }^{5,6}{ }^{(D)}$, Robert Adamski ${ }^{7}$, Mohamed I. Sakran ${ }^{8,9}$ \\ and Dorota Siuta $7, *$ (iD
}

Citation: Zahid, M.; Lodhi, M.; Rehan, Z.A.; Tayyab, H.; Javed, T.; Shabbir, R.; Mukhtar, A.; EL Sabagh, A.; Adamski, R.; Sakran, M.I.; et al. Sustainable Development of Chitosan/Calotropis procera-Based Hydrogels to Stimulate Formation of Granulation Tissue and Angiogenesis in Wound Healing Applications. Molecules 2021, 26, 3284. https:// doi.org/10.3390/molecules26113284

Academic Editor: Katarína Valachová

Received: 28 April 2021

Accepted: 27 May 2021

Published: 29 May 2021

Publisher's Note: MDPI stays neutral with regard to jurisdictional claims in published maps and institutional affiliations.

Copyright: (c) 2021 by the authors. Licensee MDPI, Basel, Switzerland. This article is an open access article distributed under the terms and conditions of the Creative Commons Attribution (CC BY) license (https:// creativecommons.org/licenses/by/ $4.0 /)$
1 Department of Chemistry, University of Agriculture, Faisalabad 38000, Pakistan; rmzahid@uaf.edu.pk (M.Z.); mk0441021@gmail.com (M.L.); hamna7575@yahoo.com (H.T.)

2 Department of Materials, National Textile University, Faisalabad 37610, Pakistan

3 College of Agriculture, Fujian Agriculture and Forestry University, Fuzhou 350002, China; mtahaj@fafu.edu.cn (T.J.); rubabshabbir28@gmail.com (R.S.)

4 Department of Agronomy, University of Agriculture, Faisalabad 38040, Pakistan; ah.mukhtar85@gmail.com

5 Department of Agronomy, Faculty of Agriculture, Kafrelsheikh University, Kafrelsheikh 33156, Egypt; ayman.elsabagh@agr.kfs.edu.eg

6 Department of Field Crops, Faculty of Agriculture, Siirt University, Siirt 56100, Turkey

7 Faculty of Process and Environmental Engineering, Lodz University of Technology, 90-924 Lodz, Poland; robert.adamski@p.lodz.pl

8 Biochemistry Section, Chemistry Department, Faculty of Science, Tanta University, Tanta 31527, Egypt; msakran@ut.edu.sa

9 Biochemistry Department, Faculty of Science, University of Tabuk, Tabuk 47512, Saudi Arabia

* Correspondence: zarehan@ntu.edu.pk (Z.A.R.); dorota.siuta@p.lodz.pl (D.S.)

\begin{abstract}
The formation of new scaffolds to enhance healing magnitude is necessarily required in biomedical applications. Granulation tissue formation is a crucial stage of wound healing in which granulation tissue grows on the surface of a wound by the formation of connective tissue and blood vessels. In the present study, porous hydrogels were synthesized using chitosan incorporating latex of the Calotropis procera plant by using a freeze-thaw cycle to stimulate the formation of granulation tissue and angiogenesis in wound healing applications. Structural analysis through Fourier transform infrared (FTIR) spectroscopy confirmed the interaction between chitosan and Calotropis procera. Latex extract containing hydrogel showed slightly higher absorption than the control during water absorption analysis. Thermogravimetric analysis showed high thermal stability of the 60:40 combination of chitosan (CS) and Calotropis procera as compared to all other treatments and controls. A fabricated scaffold application on a chick chorioallantoic membrane (CAM) showed that all hydrogels containing latex extract resulted in a significant formation of blood vessels and regeneration of cells. Overall, the formation of connective tissues and blood capillaries and healing magnitude decreased in ascending order of concentration of extract.
\end{abstract}

Keywords: hydrogels; chitosan; granulation; wound healing; sustainability; Calotropis procera

\section{Introduction}

Wound healing is considered to be a promising subject that aims to repair or enrich the functioning of an impaired organ or tissue. As per the World Health Organization (WHO), about 2.8 million people suffered from wounds, and 146,000 deaths occurred due to road traffic accidents and war in Pakistan during 2019 [1]. For this reason, wound bandages are utilized to treat tissue damage and skin injuries that occur due to accidents, ailments, and surgery [2]. Wound healing comprises combined biochemical and cellular actions directed to recovering the potency of damaged muscles with the restoration of mechanical and efficient reliability [3]. It involves the redevelopment of operative skin illustrated by 
cooperative and vigorous actions including the formation of an extracellular matrix (ECM) following the cell relocation, proliferation, and segregation [4]. The approach of wound healing is to exchange lost or degraded organs or tissues with composite or polymeric scaffolds consisting of the specified characteristics of living cells, with the purpose of tissue redevelopment and return of usual functions [5]. Wound healing agents such as scaffolds and bandages have gained wide importance as they impart primary biological reinforcement to the substituted tissues until sufficient ECM formation occurs [6]. For appropriate wound recovery, injured muscles must be replaced with biocompatible scaffolds. Therefore, in recent years, improvements have taken place in the formulation of new kinds of dressing substances particularly using biocompatible molecules $[7,8]$. Dressing substances must ensure germ-free and harmless environments to enhance epidermal cell movement and have such flexible and soft properties that make their removal easy after healing [9-11]. Advanced dressings consist of foams and films based on polymers and make connections with the surroundings, prevent penetration of microbes, and stimulate epithelization without scar formation [12].

Materials must have the capacity to absorb water over time for adequate wound recovery [13]. With the introduction of moist wound healing theory, hydrogel dressings have gained wide importance because of their potential to maintain and ensure a moist and soft environment [8]. The mechanical properties of hydrogels resemble soft tissues, supporting and enhancing the healing process and copying the morphological and operative features of tissues themselves [14]. Hydrogels are insoluble with 3D structures formed by different hydrophilic polymers such as chitosan, alginate, and cellulose [15]. These consist of crosslinked and semisolid macromolecular networks that are able to absorb significant amounts of biological fluids and moisture contents. Hydrogels based on natural materials are advantageous because of their safe nature, biocompatibility, and biodegradability. Hydrogels are appropriate scaffolds for the healing of all four phases of the wound $[16,17]$.

Being a natural polymer, chitosan is usually employed in wound healing applications [18]. Chitosan is the most important material that boosts granulation, inflammatory cell function, and cell proliferation in wound healing. It has a structural resemblance to glycosaminoglycan, a protein present in the ECM [19], and has the ability to promote histoarchitectural muscle networks. Owing to its macrophage behavior, powerful bactericidal effect, hemostatic properties, biocompatibility, wound healing properties, excellent biodegradability, low toxicity, low manufacturing rate, and high accessibility, chitosan has been widely utilized in the biomedical domain [20-22]. Certain groups such as $\mathrm{NH}_{2}$ and $\mathrm{OH}$ present in the chitosan provide the opportunity of interaction with biological molecules and other polymers [23].

Bioactive dressings grouped with natural or synthetic pharmaceutically active mediators are assumed to enhance wound healing with an artistic exterior. The current emphasis on the preference of bio-based herbal agents in respect to their easy access, negligible toxicity, and multifunctional roles has enabled their incorporation in wound dressings. Calotropis procera (sodom apple) was assessed for its wound healing capability depending upon its conventional utility. Calotropis procera latex is described as having antimicrobial, wound healing, anti-inflammatory, and analgesic properties [24]. The granulation tissue consists of protein and DNA components that specify protein level formation, and the mutagenic profile and above-stated characteristics of this plant are specifically responsible for wound healing. By significantly expanding epithelization, collagen, synthesis of protein, and DNA, thus causing a decline in cut size, latex of sodom apple meaningfully increased healing progression [25]. Both above-mentioned materials have wound healing and antimicrobial properties. Chitosan has been utilized as a hydrogel and Calotropis procera extract has been utilized directly on wound sites [26] to observe the healing process. Both have been utilized separately as bioactive materials. Previously, no hydrogel incorporating Calotropis procera latex extract with any combination of polymers has been reported. Therefore, in the current study, we aim to achieve sustainable development of hydrogel incorporating latex extract of Calotropis procera in chitosan using freeze-thawing 
and investigate their chemical interaction, surface morphology, swelling capability, thermal stability, and healing potential.

\section{Results}

\subsection{Preparation of Hydrogels}

In this experiment, CS/C $p$-LE-based hydrogels were synthesized by freeze-thawing to examine their collective impact on wound healing. A schematic illustration of CS/Cp-LE hydrogels is shown in Figure 1.

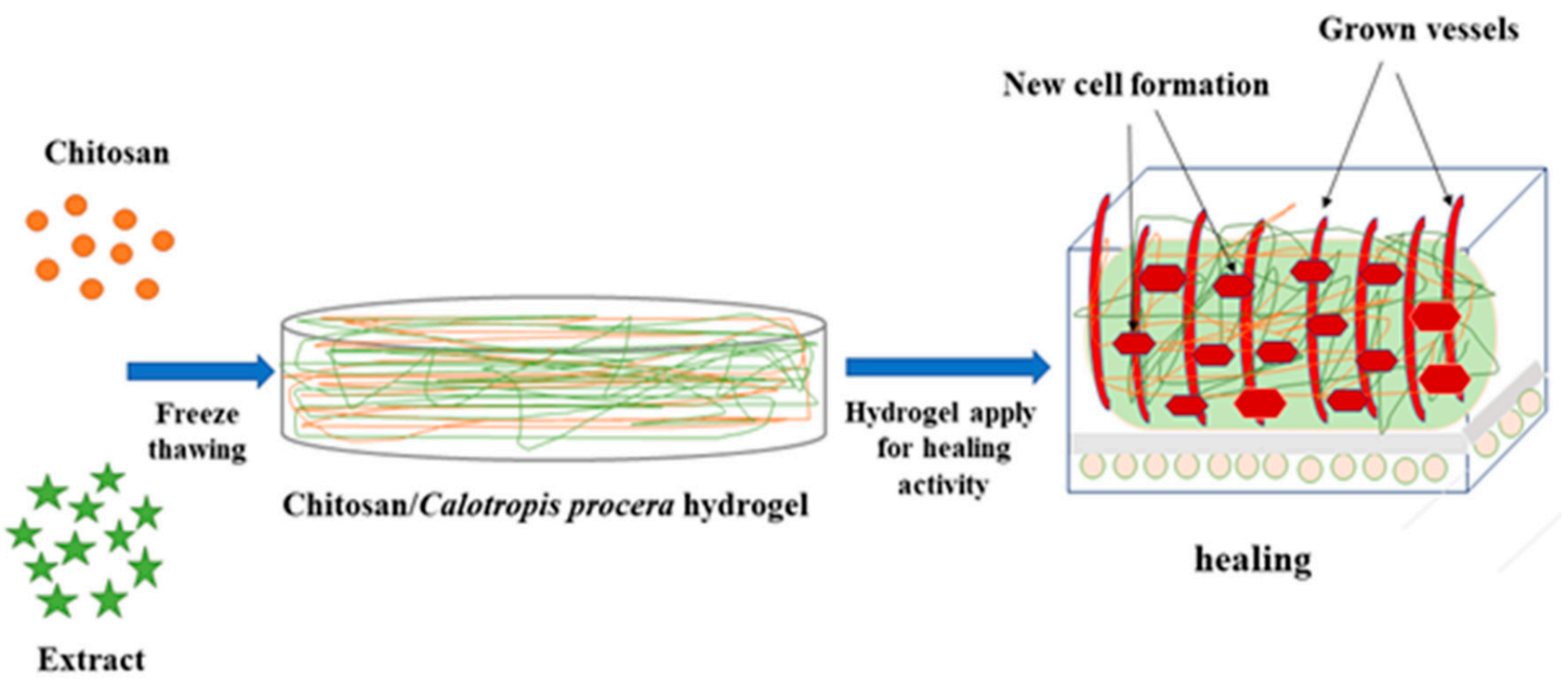

Figure 1. Schematic representation of CS/Cp-LE hydrogels.

\subsection{Fourier Transform Infrared Spectroscopy (FTIR)}

The chemical interaction between the polymeric material and plant extract was studied by FTIR. Samples C-1, C-2, C-3, and C-4 consisted of different weight percent ratios of $1 \%$ concentration solution of CS and Cp-LE, namely 60/40, 70/30, 80/20, and 90/10, respectively (Table 1). The control hydrogel showed characteristic peaks of CS (Figure 2). The broad peak at $3300-3350 \mathrm{~cm}^{-1}$ was due to $\mathrm{N}-\mathrm{H}$ and $\mathrm{O}-\mathrm{H}$ stretching, the peak at $1640 \mathrm{~cm}^{-1}$ was assigned to amide I, while the peak at $1553 \mathrm{~cm}^{-1}$ showed the presence of $\mathrm{C}-\mathrm{CH}_{3}$. C-H and $\mathrm{O}-\mathrm{H}$ deformation peaks were present around $1400 \mathrm{~cm}^{-1}$. The band at $1023 \mathrm{~cm}^{-1}$ indicated bending of $\mathrm{C}-\mathrm{O}$ [27]. The band position from 1020-1078 $\mathrm{cm}^{-1}$ represents $\mathrm{C}-\mathrm{O}$ stretching. From the literature, characteristic peaks of $\mathrm{C} p$-LE reviewed show a broad band of 3350 to $3450 \mathrm{~cm}^{-1}$ due to the $\mathrm{O}-\mathrm{H}$ stretching of aliphatic fractions present in polysaccharides [28]. The small peaks at 2919 to $2850 \mathrm{~cm}^{-1}$ were assigned to the C-H stretching of $\mathrm{CH}_{3}$ and $-\mathrm{CH}_{2}$ groups and cellulose fiber contents in $\mathrm{Cp}$-LE [29,30]. The peak at $1151 \mathrm{~cm}^{-1}$ was due to the $\mathrm{C}-\mathrm{O}$ bond stretching of cellulose and hemicellulose [31-33].

Table 1. Sample concentration of chitosan (CS) and Calotropis procera latex extract.

\begin{tabular}{ccc}
\hline Samples & CS $(\mathbf{W t} \%)$ & $C p$-LE $(\mathbf{W t} \mathbf{\%})$ \\
\hline Control & 100 & nil \\
C-1 & 60 & 40 \\
C-2 & 70 & 30 \\
C-3 & 80 & 20 \\
C-4 & 90 & 10 \\
\hline
\end{tabular}

All hydrogels with $C p$-LE displayed peaks almost at the same positions where peaks of the control sample (Figure 2) and C $\mathrm{C}$-LE were present. The peak in the region of $3150-3350 \mathrm{~cm}^{-1}$ represents N-H and O-H stretching as compared to the control sample, 
and a shift occurs due to the interaction of both CS and Cp-LE. The intensity of a N-H stretching peak depends on $\mathrm{H}$-bonding and moisture content. The peak in the range of 2919 to $2850 \mathrm{~cm}^{-1}$ in CS/Cp-LE hydrogels was due to the C-H stretching of methyl and methylene groups and cellulose fiber contents that confirmed the presence of C $p$-LE in CS/Cp-LE hydrogels. A peak within a range of $1650-1660 \mathrm{~cm}^{-1}$ represented amide I, and a peak of $1546 \mathrm{~cm}^{-1}$ showed the presence of amide II; minor shifts occurred in their positions due to crosslinking. The deformation peaks of $\mathrm{O}-\mathrm{H}$ and $\mathrm{C}-\mathrm{H}$ are present in the $1416 \mathrm{~cm}^{-1}$ region in Figure 2. The peak present in the C-1, C-2, C-3, and C-4 hydrogels at $1151 \mathrm{~cm}^{-1}$ position was due to the $\mathrm{C}-\mathrm{O}$ bond stretching of cellulose and hemicellulose that was absent in the control sample. However, FTIR spectra of CS/Cp-LE hydrogels indicated a strong interaction between chitosan and Calotropis procera latex extract.

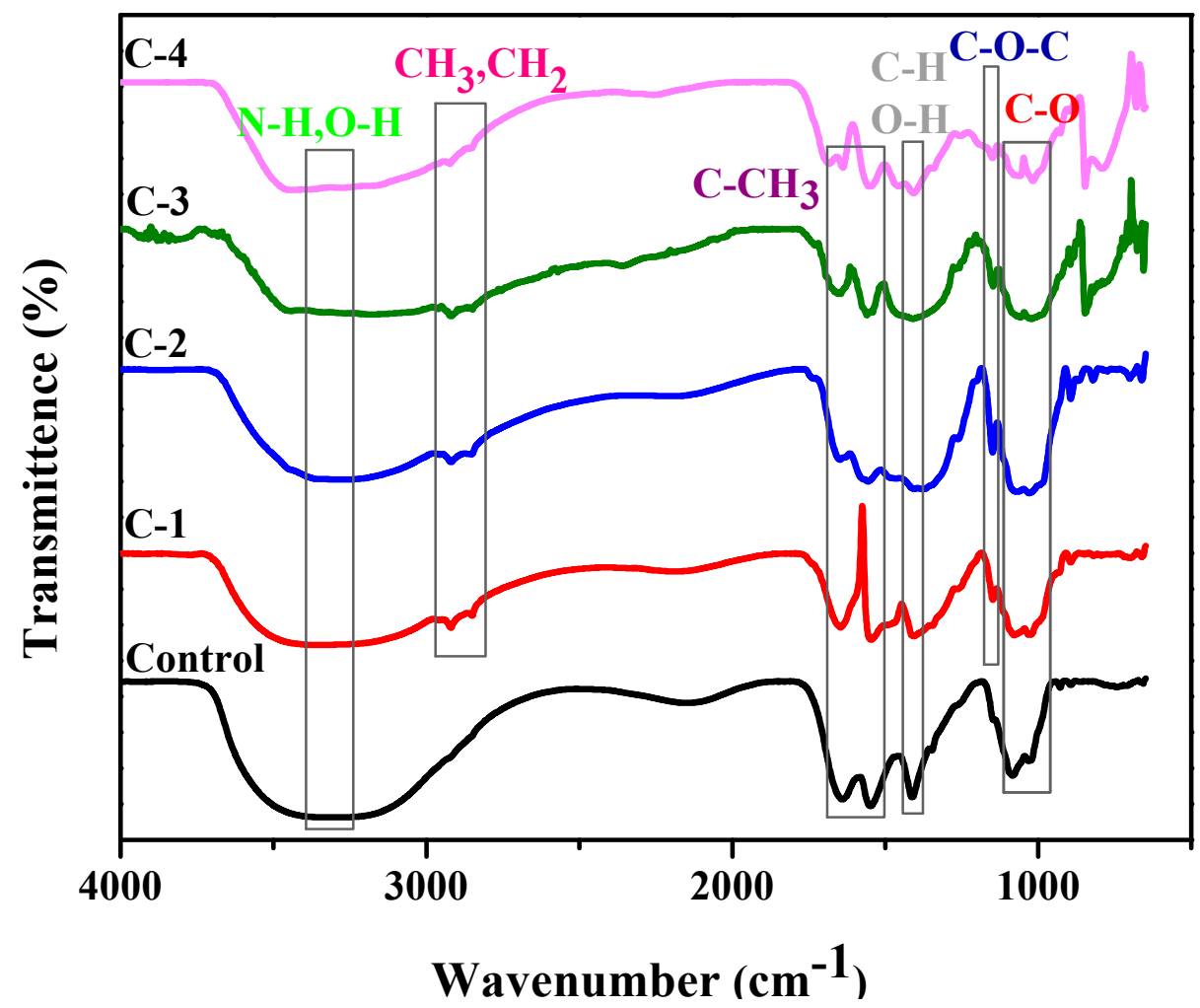

Figure 2. FTIR analysis of CS/Cp-LE-based hydrogels.

\subsection{Scanning Electron Microscopy (SEM)}

Scanning electron microscopy was used to analyze the morphology, structure, and size of the synthesized material. Morphology and porosity of control and all CS/CpLE hydrogels were examined, and their SEM images are given in Figure 3. The control hydrogel containing only CS polymer showed open pores. These microstructural open pores were interlinked in the whole surface. Control hydrogels contain a highly porous structure and smooth surface consisting of CS material only, as stated in the literature where with the increase in CS ratio, the hydrogel structure becomes looser [34]. SEM images of C-1, C-2, C-3, and C-4 hydrogels with varying concentrations of CS/C $p$-LE, namely 60/40, 70/30, 80/20, and 90/10, respectively, are shown in Figure 3. All hydrogels containing $\mathrm{C} p$-LE show a less porous surface compared to that of the control hydrogel because their surface is covered with $C p$-LE content. However, the number of pores in C-1 is greater than that in C-2, C-3, and C-4, possibly due to the decreasing C $p$-LE ratio of C-2, C-3, and C-4. This was evident from the SEM images: as the $C p$-LE ratio decreased in the hydrogels, their porosity also decreased in descending order of $C p$-LE weight percent ratio. 

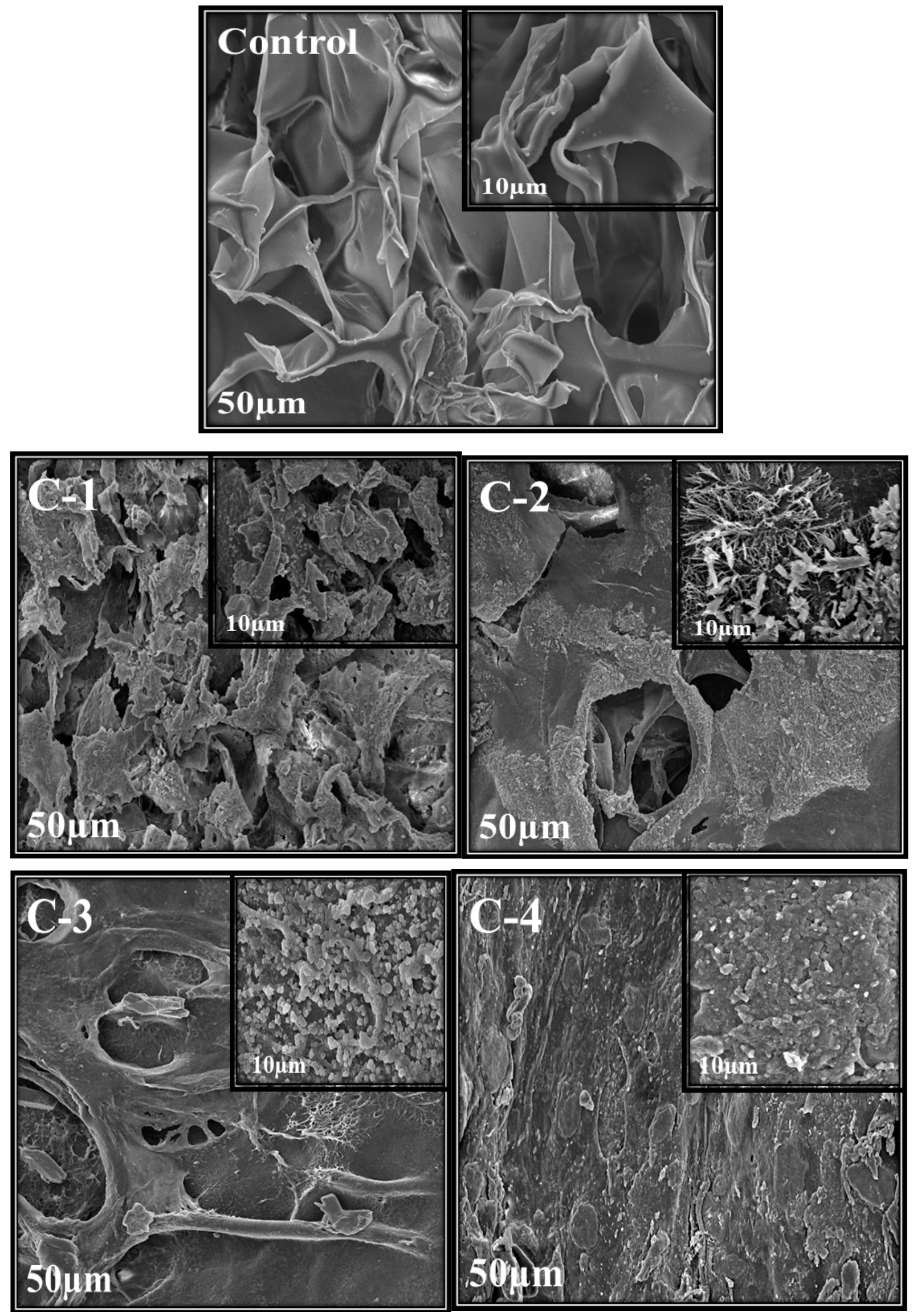

Figure 3. SEM images of CS/Cp-LE hydrogels: control, C-1, C-2, C-3, and C-4; at $\times 1000$ and $\times 2500$ magnifications. 


\subsection{Swelling Analysis}

A swelling test was performed to determine the liquid absorption capacity of the hydrogels. Each sample of hydrogel was soaked in a saline solution of $\mathrm{NaCl}$ in Petri dishes for $24 \mathrm{~h}$. Swelling behavior was determined at different time intervals of $0.5,1,2,3$, and $24 \mathrm{~h}$. After passing each specified time, their swelling percentage values were noted by removing each sample with the help of forceps from the solution and measuring its wet weight using an electronic balance. All samples revealed a time-dependent swelling profile, where their highest absorption value was reached within 1 to $2 \mathrm{~h}$, as shown in Figure 4. It can be observed in Figure 4 that the control hydrogels exhibited minimum water absorption as compared to the hydrogels containing $C p$-LE, which showed slightly higher liquid absorption. This may be due to the addition of $C p$-LE in the hydrogels.

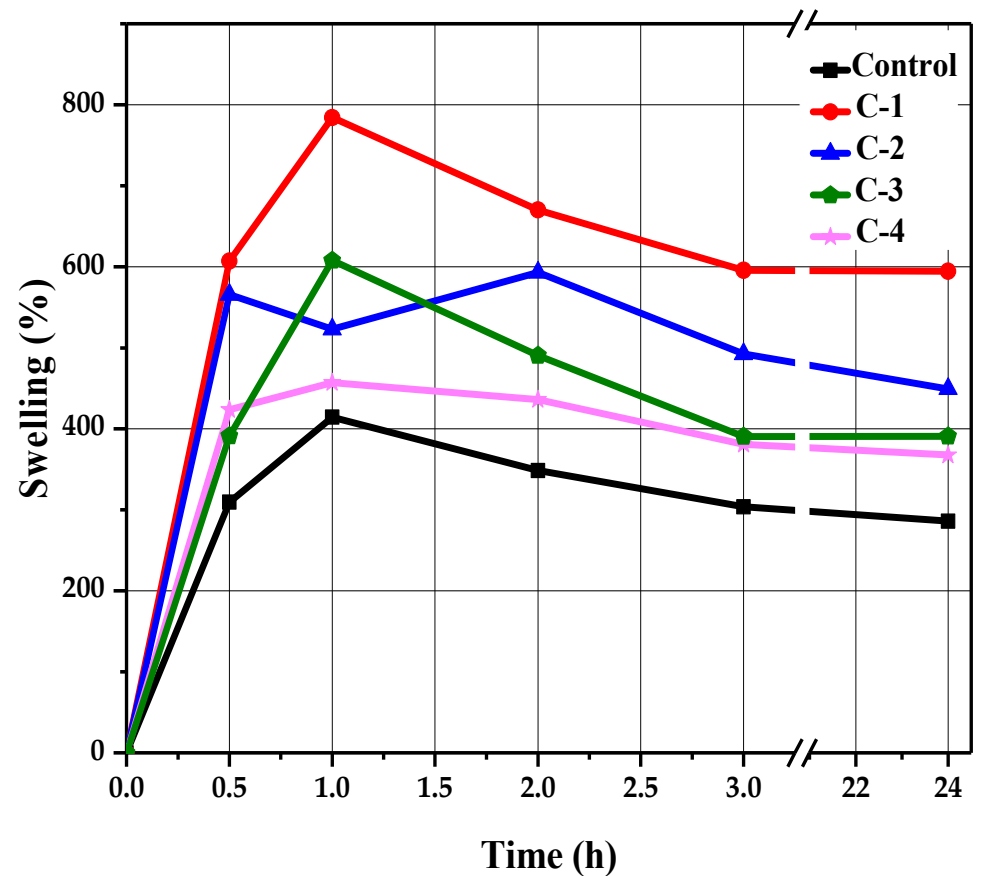

Figure 4. The swelling trend of CS/C $p$-LE-based hydrogels.

The control sample reached a maximum swelling value of $414 \%$ within $1 \mathrm{~h}$ (Figure 4 ). After that, no significant changes occurred, but low absorption values were apparent compared to hydrogels with $C p$-LE. As the $C p$-LE quantity of C-1, C-2, C-3, and C-4 hydrogels increased, so did their swelling ratio. Sample $\mathrm{C}-1$ exhibited a relatively higher swelling ratio than other hydrogels. It showed the highest swelling ratio value of $784 \%$ at $1 \mathrm{~h}$ and $227 \%, 251 \%, 223 \%$, and $222 \%$ at time intervals of $0.5,2,3$, and $24 \mathrm{~h}$, respectively. Sample C-2 showed a maximum absorption value of $593 \%$ at $2 \mathrm{~h}$ and $204 \%, 189 \%$ and $162 \%$, and $178 \%$ at $0.5,1,3$, and $24 \mathrm{~h}$, respectively. Sample C-3 showed a maximum absorption value of $607 \%$ at $1 \mathrm{~h}$, whereas $185 \%, 223 \%, 185 \%$, and $185 \%$ swelling values were observed at $0.5,2,3$, and $24 \mathrm{~h}$, respectively. Sample C-4 showed the highest swelling ratio value of $457 \%$ at $1 \mathrm{~h}$, whereas $199 \%, 205 \%, 172 \%$, and $179 \%$ swelling values were observed at $0.5,2$, 3 , and $24 \mathrm{~h}$, respectively.

\subsection{Thermogravimetric Analysis}

The stability and thermal degradation of the CS/Cp-LE hydrogels were studied using TGA analysis. Figure 5 shows the TGA curves of control for C-1, C-2, C-3, and C-4 hydrogels. A profile of TGA curves showed weight loss in three stages for all hydrogels. All hydrogel samples displayed the first degradation stage in a temperature range of 84 to $232{ }^{\circ} \mathrm{C}$; this initial weight loss occurred due to the removal of water bound with CS and was $4 \%$ for control (CS) and 1\% for all other CS/Cp-LE hydrogels. A second decomposition 
stage occurred from 224 to $339{ }^{\circ} \mathrm{C}$ (Figure 5), and the weight loss that occurred in the second stage was $28 \%$ for control, $3 \%$ for C-1, 10\% for C-2, 15\% for C-3, and $12 \%$ for C-4 hydrogel, and this stage corresponded to the oxidative and thermal decomposition of chitosan and removal of volatile products [35]. While comparing the second weight loss of the control hydrogel to C-1, C-2, C-3, and C-4 hydrogels, it was observed that the control hydrogel showed a $28 \%$ weight loss, which is higher than that observed for the other CS/Cp-LE hydrogels, possibly due to the crosslinking between CS and C $p$-LE plant material. Of all hydrogels, C-1 showed a quite low weight loss of 3\%.

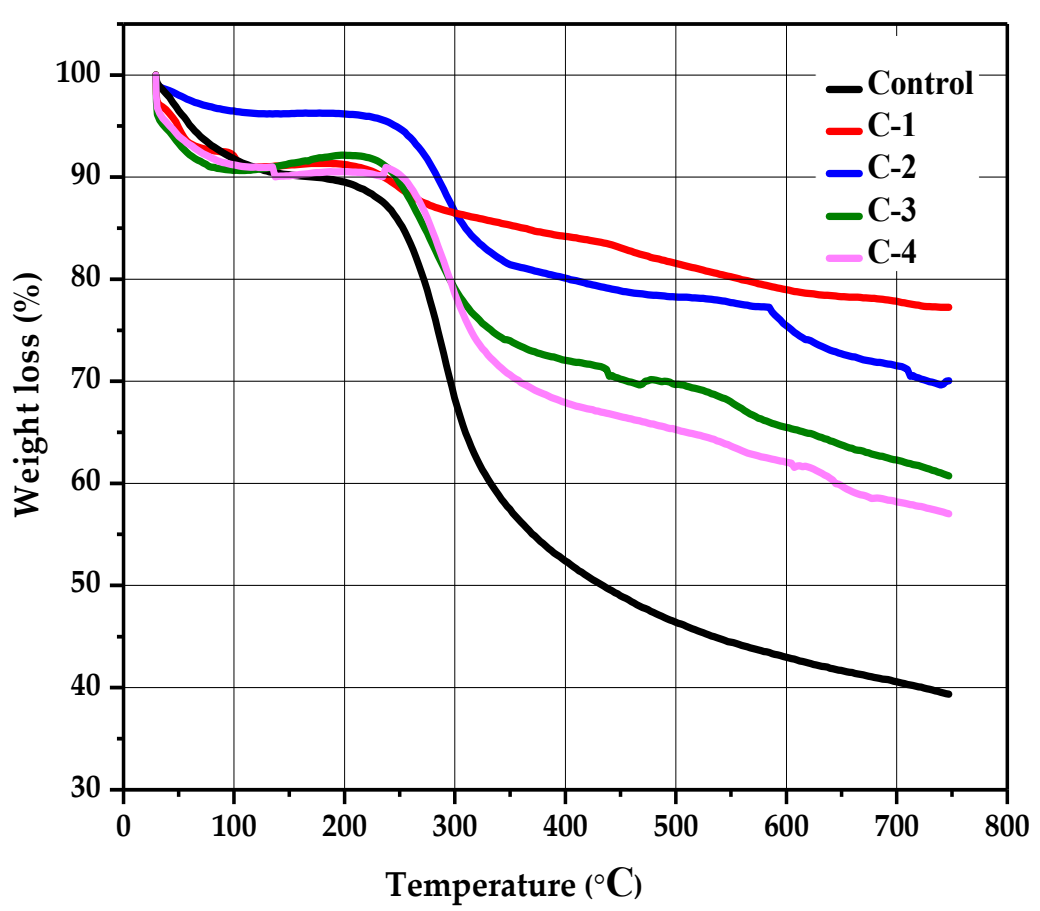

Figure 5. Thermogravimetric analysis of CS/C $p$-LE-based hydrogels.

There is also a third decomposition stage shown in the hydrogels, starting at $327^{\circ} \mathrm{C}$ and ending at $621^{\circ} \mathrm{C}$, where weight loss occurred due to the char residue of $14 \%$ for the control group, while weight loss for the other CS/Cp-LE hydrogels was less than that in the control (Table 2). Char was formed during the second decomposition stage [36].

Table 2. TGA analysis of control, C-1, C-2, C-3, and C-4 hydrogels.

\begin{tabular}{ccccc}
\hline Sample & Stages & T-onset $\left({ }^{\circ} \mathbf{C}\right)$ & T-endset $\left({ }^{\circ} \mathbf{C}\right)$ & W (\%) \\
\hline \multirow{3}{*}{ Control } & I & 84.7 & 214.8 & 4 \\
& II & 249.8 & 339.8 & 28 \\
& III & 353.6 & 621.4 & 14 \\
\hline \multirow{2}{*}{ C-1 } & I & 99.7 & 202.3 & 1 \\
& II & 224.8 & 259.8 & 3 \\
& III & 327.3 & 587.1 & 6 \\
\hline \multirow{2}{*}{ C-2 } & I & 94.7 & 224.8 & 1 \\
& II & 259.8 & 319.2 & 10 \\
\hline \multirow{2}{*}{ C-3 } & III & 349.8 & 584.6 & 1 \\
& I & 79.7 & 214.8 & 15 \\
\hline & II & 244.9 & 324.8 & 9 \\
\hline \multirow{2}{*}{ C-4 } & III & 358.6 & 598.5 & 1 \\
& I & 92.4 & 232.3 & 6 \\
\hline
\end{tabular}


The C-1 hydrogel showed the highest thermal stability, and the control hydrogel showed the lowest thermal stability of all hydrogel samples. As the Cp-LE ratio of the hydrogel samples decreased, so did the thermal stability, as C-2 showed less thermal stability than C-1, C-3 showed less thermal stability than C-2, and so on. C $p$-LE contents in the hydrogel impart stability possibly due to the strong interaction between the CS and Cp-LE blend that may protect them from decomposing during heat and reduce their mass loss during thermogravimetric analysis. For all hydrogels, Table 2 shows the starting region of thermal decomposition (T-onset) and end region (T-endset). $\mathrm{W}$ represents the percentage of weight loss.

\subsection{Chorioallantoic Membrane (CAM) Assay}

A CAM assay was executed to measure the healing capability of CS/Cp-LE hydrogels and the growth of new connective tissues and microscopic blood capillaries (angiogenesis). After the hydrogels were implanted on the cut surfaces of eggs, they were covered with parafilm and paper tape to prevent any fungal infection. All eggs were placed in the incubator at $37^{\circ} \mathrm{C}$. After the completion of 14 days, the eggs were removed from the incubator, their images were taken with a light microscope, and the response of the implanted hydrogels was examined on each egg (Figure 6).
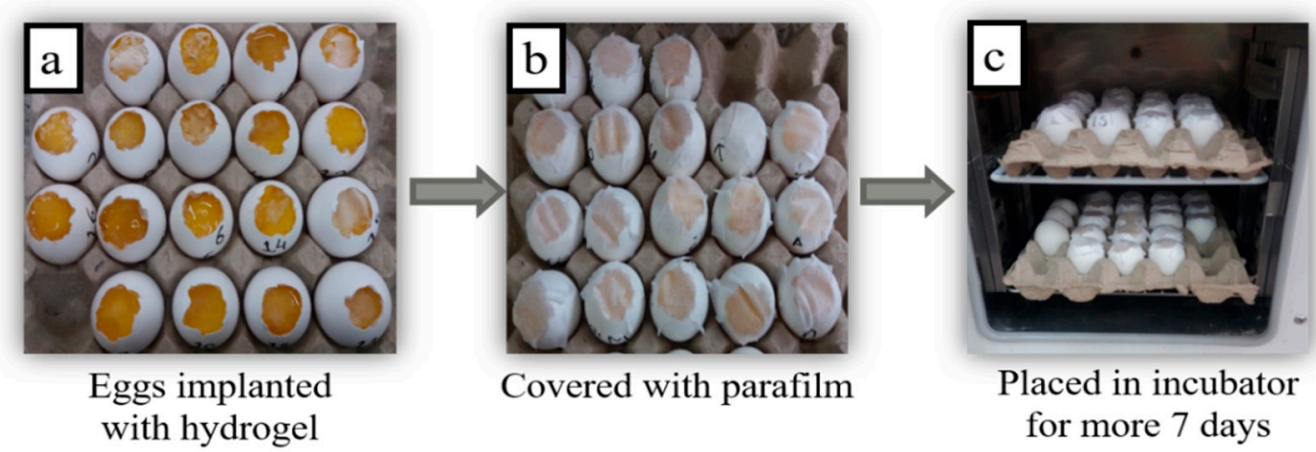

Figure 6. Stepwise handling of eggs for the CAM assay.

The microscopic images of eggs implanted with the control hydrogel (CS) exhibited much less healing, while eggs implanted with the hydrogel samples C-1, C-2, C-3, and C-4 displayed growth of regenerated cells and blood vessels compared to the control hydrogel. $C p$-LE with CS exhibited significant healing properties. The C-1 hydrogel showed significantly enhanced formation of connective tissues and blood capillaries on the chorioallantoic membrane as compared to all CS/Cp-LE hydrogels after 14 days (Figure 7), while the C-2 hydrogel showed a thick formation of blood vessels. The C-3 and C-4 hydrogels showed a comparatively low formation of new cells and blood vessels as compared to the C-2 hydrogel, due to the low concentration of C $p$-LE. As the Cp-LE ratio decreased in the hydrogels, the granulation tissue formation potential of hydrogel also decreased. Overall, it can be concluded that the CS/Cp-LE hydrogels showed good healing potential compared to the control sample.

Both chitosan and the Calotropis procera latex extract displayed a significantly high healing capability (Figure 7). In the previous literature, it has also been stated that Calotropis procera has wound healing properties. Rasik et al. [25] applied a latex solution of Calotropis procera on a guinea pig back. This increased the speed of tissue granulation, ensured increased blood vessel formation, and increased epithelization. Aderounmua et al. [37] applied Calotropis procera latex to rabbits for 21 days, which resulted in the formation of the granulation tissues and reduction of the wound site. The possible reason behind this mechanism might be the presence of phytochemicals such as tannins, flavonoids, and alkaloids in the latex of plants [38]. These are known to improve wound healing because of their antimicrobial and healing properties that increase epithelization rate and blood vessel formation and facilitate wound contraction [39]. Latex has especially been found to 
increase wound healing by encouraging a distinct growing formation of DNA, protein, and collagen [40]. However, in addition to the latex of Calotropis extract remarkably affecting healing at different stages of tissue repair, it seems that the concentration of latex extract plays a crucial role in healing capability.

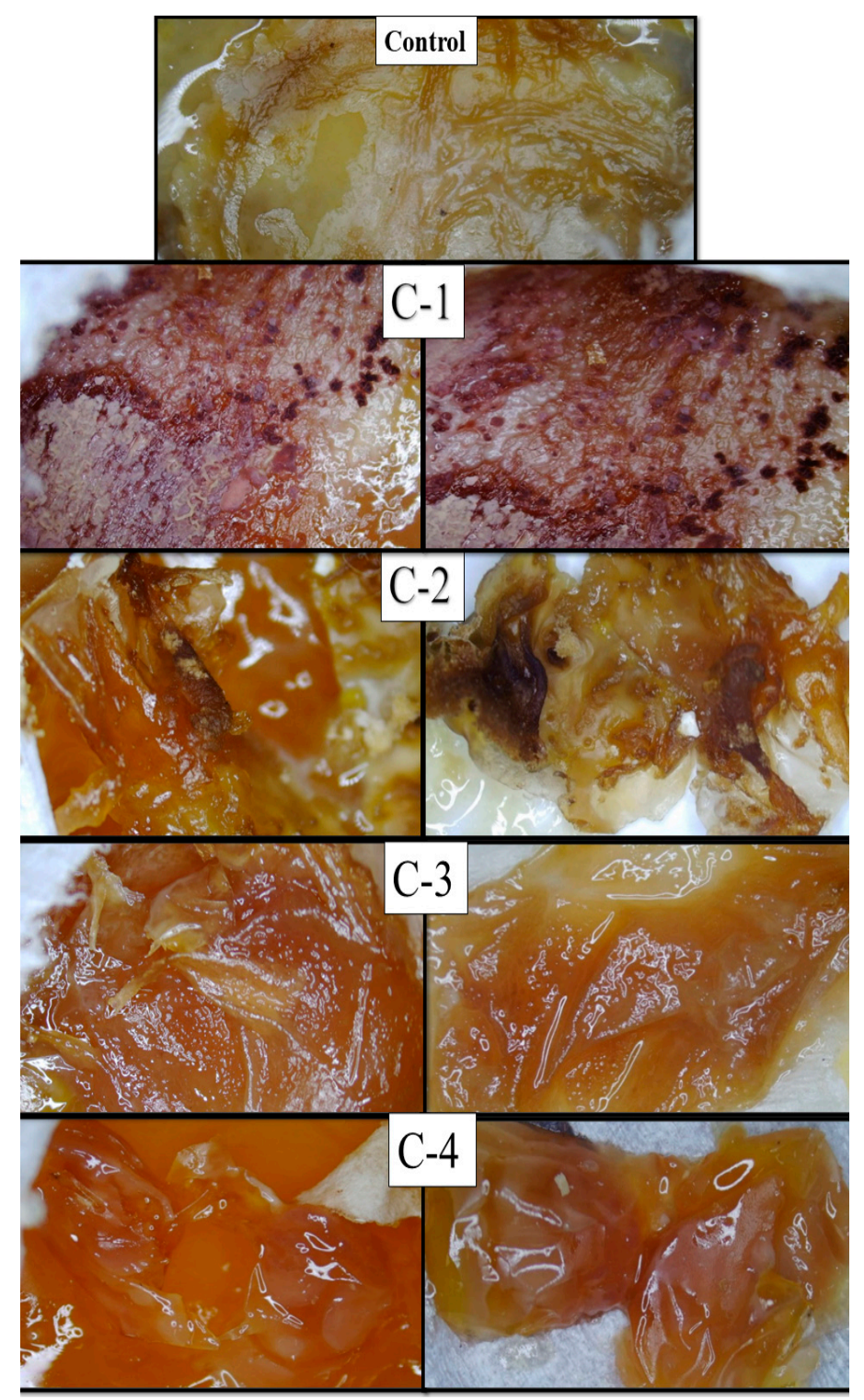

Figure 7. Microscopic images of fertilized eggs implanted with CS/Cp-LE hydrogels.

\section{Materials and Methods}

\subsection{Chemicals and Preparation Methods}

Medical grade chitosan powder from chitin of crab shells was purchased from Daejung Chemical (Si-Heung, Korea). Degree of deacetylation (DD), viscosity ( $\mu, 1 \%$ in $1 \%$ acetic acid, $20{ }^{\circ} \mathrm{C}$ ), and viscosity average molecular weight (Mv) are equal to $82.6-87.5 \%$, 351-750 mPas, and 310-375 kDa, respectively [41]. Calotropis procera plant extract was collected from plants located at the University of Agriculture, Faisalabad, Pakistan $\left(31.4278^{\circ} \mathrm{N}\right.$, $\left.73.0758^{\circ} \mathrm{E}\right)$. Absolute alcohol, sodium hydroxide $(\mathrm{NaOH})$, sodium chloride $(\mathrm{NaCl})$, and acetic acid $\left(\mathrm{CH}_{3} \mathrm{COOH}\right)$ were obtained from Sigma-Aldrich (Burlington, VT, USA).

\subsubsection{Calotropis procera Extract Preparation}

Firstly, the latex of Calotropis procera (sodom apple) plant was collected by breaking the stem of the plants located behind the new science block of the University of Agriculture, 
Faisalabad, Pakistan $\left(31.4278^{\circ} \mathrm{N}, 73.0758^{\circ}\right.$ E). After collection, the latex extract was slightly diluted and filtered using Whatman filter paper and left until complete filtration had taken place. After that, the filtrate was collected in a bottle and stored at $4{ }^{\circ} \mathrm{C}$ in a refrigerator [27].

\subsubsection{Preparation of Chitosan Solution}

A $1 \%$ stock solution of chitosan was prepared by mixing $1 \mathrm{~g}$ of chitosan in $100 \mathrm{~mL}$ of distilled water. After that, two drops of $1 \%$ acetic acid were added [28]. Then the solution was placed on a magnetic stirrer for $12 \mathrm{~h}$ at room temperature for the complete mixing of chitosan, and two more drops of acetic acid were added after $6 \mathrm{~h}$. After $12 \mathrm{~h}$ of stirring, a clear homogenized chitosan solution was obtained and stored in the refrigerator at $4{ }^{\circ} \mathrm{C}$.

\subsubsection{Synthesis of CS/Cp-LE Hydrogel}

Hydrogel was synthesized by mixing prepared CS solution and Cp-LE through freezethawing. The concentrations mentioned in Table 1 show the weight percent ratio of $C p$-LE and CS solution.

These concentrations were poured into Petri dishes and stirred until the solution became clear and were then placed in the refrigerator at $-20^{\circ} \mathrm{C}$ for overnight. A three molar (3 M) solution of sodium hydroxide was made in distilled water. Frozen samples were then coagulated with sodium hydroxide solution and refrozen for $12 \mathrm{~h}$ at $-20^{\circ} \mathrm{C}$. Then, the samples were washed two times with absolute alcohol and further washed two times with distilled water to neutralize the samples' $\mathrm{pH}$. In the end, neutral samples were thawed at $37^{\circ} \mathrm{C}$ in the oven for $24 \mathrm{~h}$.

\subsection{Characterization of Hydrogels}

\subsubsection{Fourier Transform Infrared Spectroscopy}

A Fourier transform infrared spectroscopic analysis (FTIR, PerkinElmer Spectrum Two, OH, USA) was carried out for the study of the chemical structure and functional groups on the material's surface. Analysis was conducted in a range of $4000-650 \mathrm{~cm}^{-1}$.

\subsubsection{Scanning Electron Microscope Imaging}

Scanning electron microscope (JSM-5910, JEOL, Akishima, Tokyo, Japan) images of the synthesized hydrogels were taken to examine the surface morphology. The operating voltage was 10 kilovolts. The samples were coated with gold using a sputter coater.

\subsubsection{Swelling Analysis}

A swelling analysis of synthesized gels was carried out in a $\mathrm{NaCl}$ saline solution at $37^{\circ} \mathrm{C}$. The three molar $(3 \mathrm{M})$ solution of sodium chloride $(\mathrm{NaCl})$ was prepared in distilled water. A considerable difference in weight between dry $\left(\mathrm{W}_{d}\right)$ and wet $(\mathrm{W})$ hydrogels was observed after specified intervals of 0.5, 1, 2, 3, and $24 \mathrm{~h}$ [29].

Equation (1) was used to measure the swelling percentage.

$$
\text { Swelling }(\%)=\frac{\mathrm{W}-\mathrm{W}_{d}}{\mathrm{~W}_{d}} \times 100
$$

\subsubsection{Thermogravimetric Analysis}

A Netzsch TG 209F1 Libra thermogravimetric system was used to check the thermal stability of CS hydrogels incorporating Cp-LE. Samples were heated from 25 to $750{ }^{\circ} \mathrm{C}$ under a nitrogen flow of $20 \mathrm{~mL} / \mathrm{min}$ at a heating rate of $10^{\circ} \mathrm{C}$ per minute.

\subsubsection{CAM Assay}

A CAM assay was carried out to determine the healing activity of the prepared hydrogels. At day zero, chick eggs were purchased from the bakery, carefully cleaned with absolute ethanol, and then placed in an incubator at $37^{\circ} \mathrm{C}$ in a humid environment. After seven days, on day 8 , sterilized hydrogels were implanted on the eggs, cutting off small 
pieces of each eggshell with a surgical blade. After that, the eggs were sealed with sterilized parafilm or covered by adhesive tape to stop any infection and returned to the incubator. Eggs were reopened on day 14, and their healing response images were captured with a light microscope to examine changes that occurred after implanting hydrogels [29].

\section{Conclusions}

The present research work explains the growth of new connective tissues and angiogenesis of chitosan-based hydrogels incorporating latex of Calotropis procera. Chitosan and latex extract were mixed through freeze-thawing, which is the best physical approach to synthesize hydrogel because no heating or reagents that may cause toxicity are required. SEM results demonstrate that higher ratios of $C p$-LE create pores in hydrogels, and their porosity decreases in descending order of $C p$-LE concentration. The synthesized CS/C $p$-LE scaffolds displayed excellent swelling capacity over the control hydrogel, which might be due to the porous structure of hydrogel. The C-1 hydrogel presented the highest thermal stability of all hydrogels. It was noticed that the C-1 hydrogel showed the highest formation of granulation tissues and blood vessels compared with the control and other hydrogels. Overall, plant extract in combination with chitosan in the form of hydrogel exhibits significant healing properties that can be further utilized in wound healing applications.

Author Contributions: Conceptualization, Z.A.R.; methodology, M.Z.; software, M.Z.; validation, Z.A.R., T.J. and A.E.S.; formal analysis, M.L.; investigation, M.Z.; resources, Z.A.R.; data curation, H.T.; writing—original draft preparation, M.Z.; writing—review and editing, M.L., T.J., R.S., Z.A.R., A.M., R.A., D.S., M.I.S. and A.E.S.; supervision, Z.A.R.; project administration, Z.A.R.; funding acquisition, D.S. and T.J. All authors have read and agreed to the published version of the manuscript.

Funding: This research received no external funding.

Institutional Review Board Statement: Not applicable.

Informed Consent Statement: Not applicable.

Data Availability Statement: The data presented in this study are available on request from the corresponding author.

Acknowledgments: The authors thank Muhammad Asad Naseer for critically reviewing the manuscript.

Conflicts of Interest: The authors declare no conflict of interest.

Sample Availability: Samples of the compounds are available from the author Maria Lodhi.

\section{References}

1. World Health Organization. Hidden Cities: Unmasking and Overcoming Health Inequities in Urban Settings; World Health Organization: Geneva, Switzerland, 2020; pp. 1-126, ISBN 9789241548038.

2. Zhang, D.; Zhou, W.; Wei, B.; Wang, X.; Tang, R.; Nie, J.; Wang, J. Carboxyl-modified poly (vinyl alcohol)-crosslinked chitosan hydrogel films for potential wound dressing. Carbohydr. Polym. 2015, 125, 189-199. [CrossRef] [PubMed]

3. Bedi, M.K.; Shenefelt, P.D. Herbal therapy in dermatology. Arch. Dermatol. 2002, 138, 232-242. [CrossRef] [PubMed]

4. Böttcher-Haberzeth, S.; Biedermann, T.; Reichmann, E. Tissue engineering of skin. Burns 2010, 36, 450-460. [CrossRef]

5. Atala, A. Tissue engineering and regenerative medicine: Concepts for clinical application. Rejuvenation Res. 2004, 7, 15-31. [CrossRef]

6. Hutmacher, D.W. Scaffold design and fabrication technologies for engineering tissues—State of the art and future perspectives. J. Biomat. Sci. Polym. Ed. 2001, 12, 107-124. [CrossRef]

7. Contreras-Ruiz, J.; Manzotti-Rodriguez, A.C. Multidisciplinary Management of Wound Healing in Diabetics. In Dermatology and Diabetes; Springer: Cham, Switzerland, 2018; pp. 199-223.

8. Gupta, B.S.; Edwards, J.V. Textile materials and structures for topical management of wounds. In Advanced Textiles for Wound Care; Woodhead Publishing: Sawston, UK, 2019; pp. 55-104.

9. Vijayakumar, V.; Samal, S.K.; Mohanty, S.; Nayak, S.K. Recent advancements in biopolymer and metal nanoparticle-based materials in diabetic wound healing management. Int. J. Boil. Macromol. 2019, 122, 137-148. [CrossRef]

10. de Lima, G.G.; de Lima, D.W.; de Oliveira, M.J.; Lugão, A.B.; Alcântara, M.T.; Devine, D.M.; de Sá, M.J. Synthesis and in vivo behavior of PVP/CMC/agar hydrogel membranes impregnated with silver nanoparticles for wound healing applications. ACS Appl. Bio Mater. 2018, 1, 1842-1852. [CrossRef] 
11. Thanh, N.T.; Hieu, M.H.; Phuong, N.T.M.; Thuan, T.D.B.; Thu, H.N.T.; Do Minh, T.; Dai, H.N.; Thi, H.N. Optimization and characterization of electrospun polycaprolactone coated with gelatin-silver nanoparticles for wound healing application. Mater. Sci. Eng. C 2018, 91, 318-329. [CrossRef]

12. Bialik-Wass, K.; Pluta, K.; Malina, D.; Barczewski, M.; Malarz, K.; Mrozek-Wilczkiewicz, A. Advanced SA/PVA-based hydrogel matrices with prolonged release of Aloe vera as promising wound dressings. Mater. Sci. Eng. C 2021, 120, 111667. [CrossRef]

13. Jin, S.G.; Kim, K.S.; Kim, D.W.; Kim, D.S.; Seo, Y.G.; Go, T.G.; Youn, Y.S.; Kim, J.O.; Yong, C.S.; Choi, H.G. Development of a novel sodium fusidate-loaded triple polymer hydrogel wound dressing: Mechanical properties and effects on wound repair. Int. J. Pharm. 2016, 497, 114-122. [CrossRef] [PubMed]

14. Berger, J.; Reist, M.; Mayer, J.M.; Felt, O.; Gurny, R. Structure and interactions in chitosan hydrogels formed by complexation or aggregation for biomedical applications. Eur. J. Pharm. Biopharm. 2004, 57, 35-52. [CrossRef]

15. Martínez-Ibarra, D.M.; Sánchez-Machado, D.I.; López-Cervantes, J.; Campas-Baypoli, O.N.; Sanches-Silva, A.; Madera-Santana, T.J. Hydrogel wound dressings based on chitosan and xyloglucan: Development and characterization. J. Appl. Polym. Sci. 2019, 136, 47342. [CrossRef]

16. Zhang, Z.; Wang, X.; Wang, Y.; Hao, J. Rapid-forming and self-healing agarose-based hydrogels for tissue adhesives and potential wound dressings. Biomacromolecules 2018, 19, 980-988. [CrossRef]

17. Fu, L.H.; Qi, C.; Ma, M.G.; Wan, P. Multifunctional cellulose-based hydrogels for biomedical applications. J. Mater. Chem. B 2019, 7, 1541-1562. [CrossRef]

18. Avadi, M.R.; Sadeghi, A.M.M.; Mohammadpour, N.; Abedin, S.; Atyabi, F.; Dinarvand, R.; Rafiee-Tehrani, M. Preparation and characterization of insulin nanoparticles using chitosan and Arabic gum with ionic gelation method. Nanomed. Nanotech. Biol. Med. 2010, 6, 58-63. [CrossRef] [PubMed]

19. Yar, M.; Gigliobianco, G.; Shahzadi, L.; Dew, L.; Siddiqi, S.A.; Khan, A.F.; Chaudhry, A.A.; Rehman, I.U.; MacNeil, S. Production of chitosan PVA PCL hydrogels to bind heparin and induce angiogenesis. Int. J. Polyme. Mater. Polym. Biomater. 2016, 65, 466-476. [CrossRef]

20. Zheng, L.Y.; Zhu, J.F. Study on antimicrobial activity of chitosan with different molecular weights. Carbohydr. Polym. 2003, 54, 527-530. [CrossRef]

21. Dongre, R.S. Introductory chapter: Multitask portfolio of chitin/chitosan: Biomatrix to quantum dot. Chitin-Chitosan Myriad Function. Sci. Technol. 2018, 1. [CrossRef]

22. Gallo, M.; Naviglio, D.; Caruso, A.A.; Ferrara, L. Applications of chitosan as a functional food. In Novel Approaches of Nanotechnology in Food; Academic Press: Cambridge, MA, USA, 2016; pp. 425-464.

23. d'Ayala, G.G.; Malinconico, M.; Laurienzo, P. Marine derived polysaccharides for biomedical applications: Chemical modification approaches. Molecules 2008, 13, 2069-2106. [CrossRef] [PubMed]

24. Meena, A.K.; Yadav, A.; Rao, M.M. Ayurvedic uses and pharmacological activities of Calotropis procera Linn. Asian J. Tradit. Med. 2011, 6, 45-53.

25. Rasik, A.M.; Raghubir, R.; Gupta, A.; Shukla, A.; Dubey, M.P.; Srivastava, S.; Jain, H.K.; Kulshrestha, D.K. Healing potential of Calotropis procera on dermal wounds in Guinea pigs. J. Ethnopharmacol. 1999, 68, 261-266. [CrossRef]

26. Buffoni, F.; Banchelli, G.; Cambi, S.; Ignesti, G.; Pirisino, R.; Raimondi, L.; Vannelli, G. Skin wound healing: Some biochemical parameters in Guinea-pig. J. Pharm. Pharmacol. 1993, 45, 784-790. [CrossRef]

27. Chaiwut, P.; Rawdkuen, S.; Benjakul, S. Extraction of protease from Calotropis procera latex by polyethylene glycol-salts biphasic system. Process Biochem. 2010, 45, 1148-1155. [CrossRef]

28. Mania, S.; Tylingo, R.; Augustin, E.; Gucwa, K.; Szwacki, J.; Staroszczyk, H. Investigation of an elutable N-propylphosphonic acid chitosan derivative composition with a chitosan matrix prepared from carbonic acid solution. Carbohydr. Polym. 2018, 179, 196-206. [CrossRef]

29. Aleem, A.R.; Shahzadi, L.; Alvi, F.; Khan, A.F.; Chaudhry, A.A.; ur Rehman, I.; Yar, M. Thyroxin releasing chitosan/collagen based smart hydrogels to stimulate neovascularization. Mater. Design. 2017, 133, 416-425. [CrossRef]

30. Poiyamozhi, A.; Sundaraganesan, N.; Karabacak, M.; Tanrıverdi, O.; Kurt, M. The spectroscopic (FTIR, FT-Raman, UV and NMR), first-order hyperpolarizability and HOMO-LUMO analysis of 4-amino-5-chloro-2-methoxybenzoic acid. J. Mol. Struct. 2012, 1024, 1-12. [CrossRef]

31. Song, K.; Zhu, X.; Zhu, W.; Li, X. Preparation and characterization of cellulose nanocrystal extracted from Calotropis procera biomass. Bioresour. Bioprocess. 2019, 6, 1-8. [CrossRef]

32. Jucá, T.L.; Ramos, M.V.; Moreno, F.B.M.B.; Viana de Matos, M.P.; Marinho-Filho, J.D.B.; Moreira, R.A.; Monteiro-Moreira, A.C.D.O. Insights on the phytochemical profile (cyclopeptides) and biological activities of Calotropis procera latex organic fractions. Sci. World J. 2013, 2013, 615454. [CrossRef]

33. Yoganandam, K.; Ganeshan, P.; NagarajaGanesh, B.; Raja, K. Characterization studies on Calotropis procera fibers and their performance as reinforcements in epoxy matrix. J. Nat. Fibers. 2020, 17, 1706-1718. [CrossRef]

34. Zarrinkhameh, M.; Zendehnam, A.; Hosseini, S.M. Fabrication of polyvinylchloride based nanocomposite thin film filled with zinc oxide nanoparticles: Morphological, thermal and optical characteristics. J. Indust. Engin. Chem. 2015, 30, 295-301. [CrossRef]

35. EL-HAFIAN, E.A.; Elgannoudi, E.S.; Mainal, A.; Yahaya, A.H.B. Characterization of chitosan in acetic acid: Rheological and thermal studies. Turk. J. Chem. 2010, 34, 47-56. 
36. Valderruten, N.E.; Valverde, J.D.; Zuluaga, F.; Ruiz-Durántez, E. Synthesis and characterization of chitosan hydrogels cross-linked with dicarboxylic acids. React. Funct. Polym. 2014, 84, 21-28. [CrossRef]

37. Aderounmua, A.O.; Omonisib, A.E.; Akingbasotec, J.A.; Makanjuolad, M.; Bejide, R.; Orafidiya, L.O.; Adelusolae, K.A. Woundhealing and potential anti-keloidal properties of the latex of Calotropis procera (Aiton) Asclepiadaceae in rabbits. Afr. J. Tradit. Complement. Altern. Med. 2003, 10, 574-579. [CrossRef]

38. Verma, V.N. The chemical study of Calotropis. Int. Lett. Chem. Phys. Astron. 2014, 1, 74-90.

39. Singhal, A.K.; Gupta, H.; Bhati, V.S. Wound healing activity of Argyreia nervosa leaves extract. Int. J. Appl. Basic Med. Res. 2011, 1, 36. [PubMed]

40. Wu, W.S.; Wang, F.S.; Yang, K.D.; Huang, C.C.; Kuo, Y.R. Dexamethasone induction of keloid regression through effective suppression of VEGF expression and keloid fibroblast proliferation. J. Investing. Dermatol. 2006, 126, 1264-1271. [CrossRef] [PubMed]

41. Adamski, R.; Siuta, D. Mechanical, structural, and biological properties of chitosan/hydroxyapatite/silica composites for bone tissue engineering. Molecules 2021, 26, 1976. [CrossRef] 